\title{
Structure and Microhardness of Titanium-Based Coatings Formed by Multichamber Detonation Sprayer
}

\author{
M. Kovaleva, ${ }^{1}$ Yu. Tyurin, ${ }^{2}$ N. Vasilik, ${ }^{3}$ O. Kolisnichenko, ${ }^{2}$ M. Prozorova, ${ }^{1}$ \\ M. Arseenko, ${ }^{1}$ V. Sirota, ${ }^{1}$ and I. Pavlenko ${ }^{1}$ \\ ${ }^{1}$ Belgorod State National Research University, Pobeda 85, Belgorod 308015, Russia \\ ${ }^{2}$ E.O. Paton Electric Welding Institute, NASU, Bozhenko 11, Kiev 03650, Ukraine \\ ${ }^{3}$ N.N. Semenov Institute of Chemical Physics, RAS, Kosygina 4, Moscow 119991, Russia \\ Correspondence should be addressed to M. Kovaleva; kovaleva@bsu.edu.ru
}

Received 14 November 2014; Accepted 3 March 2015

Academic Editor: Martin Kroger

Copyright (c) 2015 M. Kovaleva et al. This is an open access article distributed under the Creative Commons Attribution License, which permits unrestricted use, distribution, and reproduction in any medium, provided the original work is properly cited.

\begin{abstract}
A series of titanium-based coatings (50-550 $\mu \mathrm{m}$ thick) on an aluminium substrate was deposited via multichamber detonation sprayer with different barrel lengths (300, 400, and 500, all in $\mathrm{mm}$ ). The titanium-based coatings obtained in these three experiments were examined by optical microscopy, scanning electron microscopy, and X-ray phase analysis. The hardness tests were carried out by the Vickers method with a test load of $50 \mathrm{~g}$. The multichamber detonation sprayer with a barrel length of $500 \mathrm{~mm}$ produced the dense layers of coating with hardness of $1300 \pm 250 \mathrm{HV}_{0.05}$ and porosity of $0.24 \%$, the best result in the experiments.
\end{abstract}

\section{Introduction}

Aluminium and its alloys are important materials of research because it is abundant in nature, cost effective, and easy to handle and represents an important category of materials due to its high technological value, electrical capacity, and wide range of industrial applications [1], especially in aerospace and household industries. By nature, aluminium alloys are highly reactive $[2,3]$. The challenge now is to protect surfaces of the aluminium parts under the most severe atmospheric conditions for a term of not less than 6-8 years.

A possible approach to increase their corrosion resistance is the deposition of a titanium coating layer $[4,5]$. A thin layer of the titanium-based coating will have no substantial effect on the weight of a structure [6].

The unique properties of titanium such as high strength to weight ratio, excellent corrosion resistance, and biocompatibility have made this material a favourable option for many applications in aerospace [7], implants [8], and corrosive environments [9]. In view of better physical-mechanical properties of titanium and its compounds, it is of interest to deposit a coating of titanium-based materials on aluminium $[10,11]$. Due to the unique properties of titanium, the titanium-based coatings are commonly used in aircraft, pipes for power plants, armour plating, naval ships, spacecraft, and missiles $[12,13]$.

At present, the process of titanium-based coatings formation is usually performed by means of thermal spray processes such as APS [14, 15], CVD [16], HVOF [17-19], cold spray $[10,20,21]$, and warm spray $[22,23]$. In conventional thermal spray processes, spraying materials are heated to high temperatures to induce complete or partial melting.

The critical velocity necessary to form the bonding of powder and substrate is relatively high for titanium due to its lower deformability related to its hcp crystal structure [24]; the reported microstructures of titanium coating tend to be porous as compared to more easily sprayable materials such as copper and aluminium [25]. Therefore, the development of new methods for making thick coatings of titanium with high density is indispensable for many industrial applications [26].

Our previous research [27] has shown that the titaniumbased coatings obtained using multichamber detonation sprayer (MCDS) are uniform and dense, with porosity below $1 \%$ and high hardness; the bulk of the coatings material is generally deformed and closely packed; however, coarse inclusions in the form of nondeformed discrete particles were detected. 


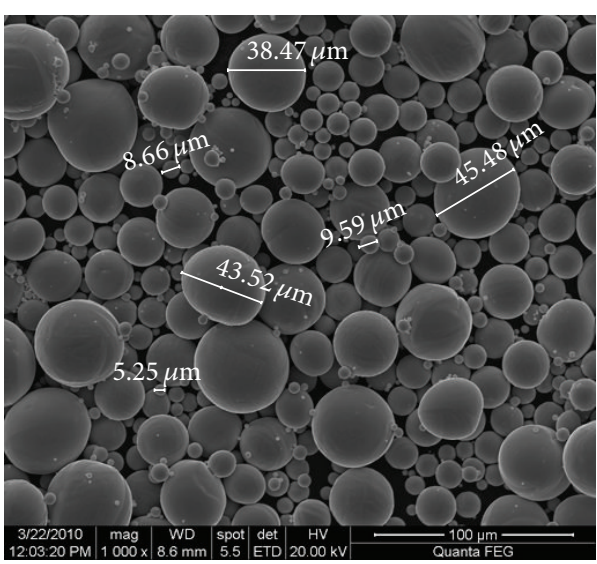

(a)

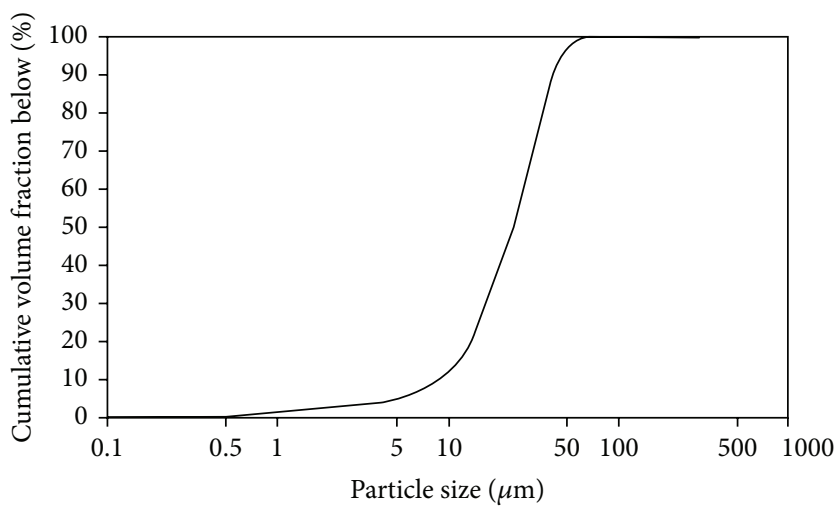

(c)

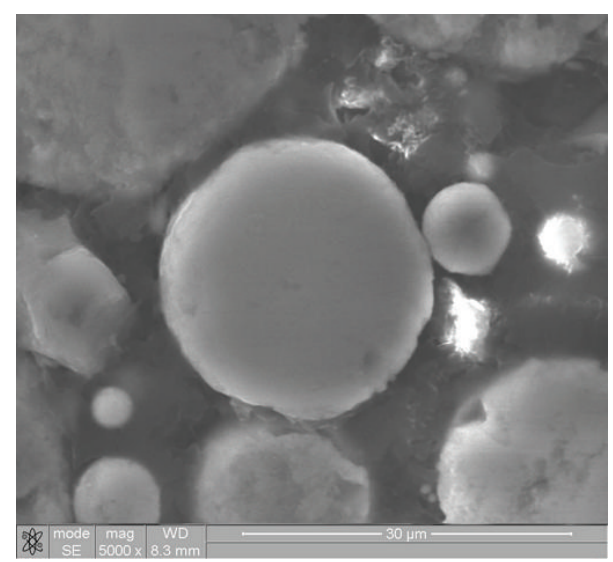

(b)

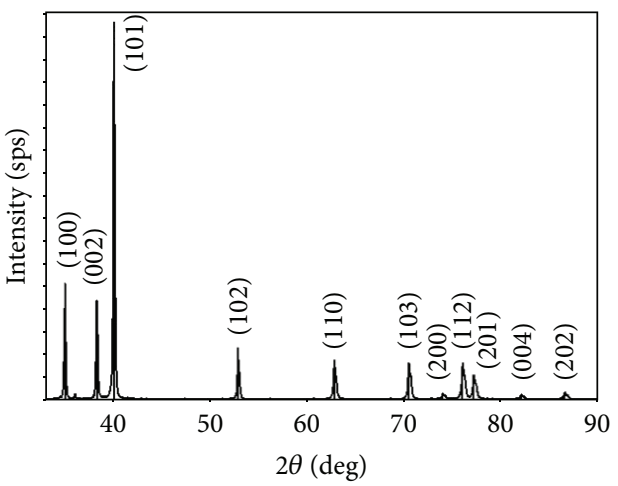

(d)

FIGURE 1: Titanium powder particles (100 wt.\% Ti): SEM image (a), micrograph of an as-polished powder cross section (b), cumulative powder size distribution measured by laser diffractometry (c), and XRD spectra (d).

The aim of this paper is to investigate the microstructure and microhardness of titanium-based coatings which were obtained by multichamber gas-dynamic accelerator with different barrel lengths $(300,400$, and 500, all in $\mathrm{mm})$.

\section{Experimental Procedure}

The titanium-based coatings were deposited using commercial pure titanium powder Gr 1 produced by plasma atomization (Raymor Industries Inc.). To study the microstructures and morphologies of the titanium powder, cross sections were prepared and analyzed by electron ion microscope (SEM: Quanta 200 3D, Quanta 600 FEG) (Figures 1(a) and 1(b)). The titanium particles had a spherical morphology (Figure 1(a)). The particle size was measured by laser diffractometry (Analysette 22 NanoTec, FRITSCH GmbH, Germany) and showed that $90 \%$ of the particles were in the supplier specified size range of -45 to $+5 \mu \mathrm{m}$ with approximately 10 vol. $\%$ below $9 \mu \mathrm{m}$ (Figure 1(c)).

Hardness of titanium powder particles was measured and was found to be at the level of $257 \pm 25 \mathrm{HV}_{0.01}$. The spray powders are dense and show no internal porosity (Figure 1(b)). The titanium powder of the phase composition and structure tested by X-ray diffraction have been certified at angle $2 \theta$ of 10 to 1000 by scanning with step $\Delta(2 \theta)=$
0.020 and an exposure time of 2.5 seconds at a point on a diffractometer Rigaku Ultima IV (Cu-K $\alpha, \lambda=0,154059 \mathrm{~nm})$. The phase analysis shows that the main phase in the titanium powder is Ti with hexagonal structure (Figure 1(d)).

Flat specimens of an aluminium alloy 6063 (Fe-0.35Cr$0.06 \mathrm{Cu}-0.10 \mathrm{Mg}-0.05 \mathrm{Ti}-0.15$, all in wt.\%) were used as substrates being sandblasted by $25 \mathrm{~A}$ F360 alumina grits prior to spraying. The dimensions of the samples were $30 \times 30 \times$ $5 \mathrm{~mm}$. The specimens were transversally cut by spark erosion, mechanically polished, and prepared by standard metallographic sample preparation methods [28] of sectioning, mounting, and polishing [29]. The samples were prepared by grinding with abrasive SiC paper $(200,500,800$, and 1,000 grades), followed by polishing with $1 \mu \mathrm{m}$ diamond slurry.

In the present study, a multichamber, vertically mounted detonation sprayer (MCDS) was employed to deposit the titanium-based coatings. The automated equipment (Figure 2) consists of (1) device for spraying, (2) standard powder feeder with a feed rate of up to $3 \mathrm{~kg} / \mathrm{h}$, (3) a standard low-pressure (max. 0.3 $\mathrm{MPa}$ ) gas panel for feeding oxygen, propane-butane, and air, (4) an automated control system for the technological process, (5) an automated manipulator for moving MCDS, and (6) a specimen holder [27, 30, 31].

A characteristic feature of MCDS is that the powder is accelerated by using the combustion products, which are 


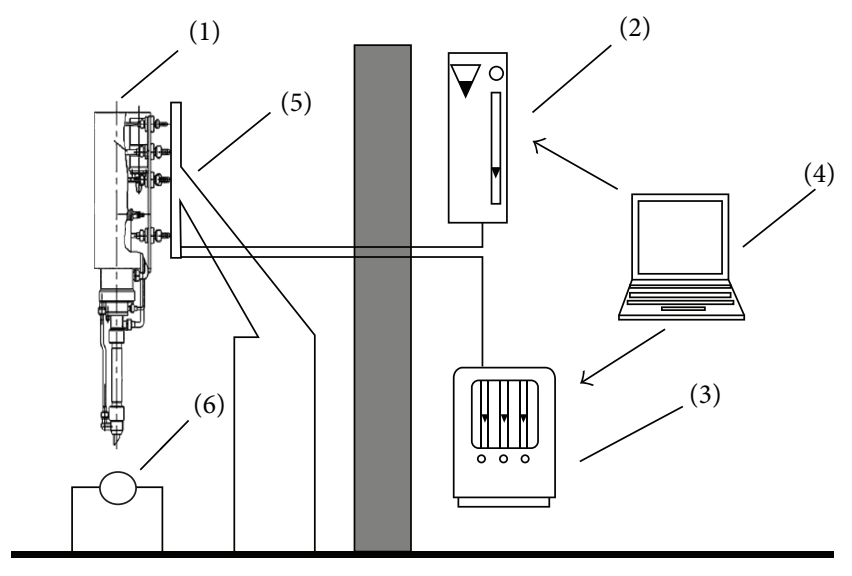

Figure 2: Equipment for deposition of coatings: (1) device for spraying; (2) standard powder feeder with feed rate of up to $3 \mathrm{~kg} / \mathrm{h}$; (3) standard low-pressure (maximum $0.3 \mathrm{MPa}$ ) gas panel for feeding oxygen, propane-butane, and air; (4) an automated control system for the technological process; (5) an automated manipulator for moving MCDS; (6) a specimen holder.

formed in the MCDS chambers and are converged before entering the barrel, where they interact with the two-phase gas-powder cloud. A standard powder feeder of the Metco Company is used to feed powder to the barrel. A continuous gas-powder jet is divided into portions and fed to the barrel by using a special device: gas-dynamic synchronizer. The process of detonation mode of combustion of the fuel mixture (propane-butane, oxygen, and air) is initiated in a special chamber by using a spark plug at a frequency of 20$50 \mathrm{~Hz}$. Then, the detonation mode of combustion spreads to the other chambers. Such initiation system and powder feeding scheme synchronize both the processes of detonation combustion and the injection of the powder into the barrel [32].

The titanium-based coatings ( $50-550 \mu \mathrm{m}$ thick) were depos-it-ed in 6 passes in the three experiments differing in barrel length $(300,400$, and 500 , all in $\mathrm{mm})$. In all cases, the powder feed rate was $800-1050 \mathrm{~g} / \mathrm{h}$, the detonation initiation frequency was $20 \mathrm{~Hz}$, the distance from the exit section of the barrel to the plate treated was $50 \mathrm{~mm}$, and the diameter of barrel was $18 \mathrm{~mm}$. Flow rate of fuel mixture components was oxygen $\left(2.2-2.7 \mathrm{~m}^{3} / \mathrm{h}\right)$, propane $30 \%+$ butane $70 \%(0.5-$ $\left.0.7 \mathrm{~m}^{3} / \mathrm{h}\right)$, and air $\left(1.2-1.4 \mathrm{~m}^{3} / \mathrm{h}\right)$.

Examinations of microstructure were carried out by scanning electron microscope (SEM: Quanta 200 3D and Quanta 600 FEG) and optical microscopy (OM, Olympus GX 51). Porosity was determined by the metallographic method with qualitative and quantitative analysis of pore geometry using an inverted optical microscope (Olympus GX51) [33]. Ten arbitrarily selected micrographs for each experimental point were registered in the optic microscope (in the bright field, magnified 500x) using SIAMS Photolab software. Local phase and analyses were conducted by X-ray powder diffractometry (Rigaku Ultima). An X-ray powder diffractometer Rigaku Ultima IV using $\mathrm{Cu}-\mathrm{K} \alpha$ monochromatic radiation (wavelength $\lambda=0.154178 \mathrm{~nm}$ ) operating at $40 \mathrm{kV}$ and $40 \mathrm{~mA}$ was employed to determine the X-ray diffraction patterns. $\mathrm{X}$-ray diffraction spectrum for phase analysis was shooting by the scheme $\theta-2 \Theta$ scan focusing by Brega-Brentano in the angular range 5-95 deg. Investigations were carried out in the $\theta / 2 \theta$ step scan mode with a step of 0.02 degrees in the $2 \theta$ range and a rate of $0.6 \mathrm{deg} . / \mathrm{min}$. Crystalline phases were identified using the ICCD PDF-2 (2008) powder diffraction database [34].

Measuring of microhardness was done using an automatic microhardness tester (DM-8B, AFFRI) via Vickers's test with a test load $50 \mathrm{~g}\left(\mathrm{HV}_{0.05}\right)$. Indentation was carried out on cross sections of samples of the coatings, with the distance between the indents being $20 \mu \mathrm{m}$. The average of ten tests was used as an indicator of coating hardness.

\section{Results and Discussion}

The typical lamellar microstructure of titanium-based coatings obtained in our experimental study is presented in Figure 3. The coatings have a thickness of about $50-550 \mu \mathrm{m}$. The analysis performed allows us to make a conclusion that the fine powder particles were heated and deformed to a state of fine lamellae and that they filled the spacing between the coarse particles to form a dense coating (Figure 3).

Electron microscopy studies of transverse sections of the system "coating-substrate" (Figures 3(a) and 3(b)) show that the bulk of the coating material deposited using barrel length of $300 \mathrm{~mm}$ is not deformed; it consists of the nondeformed discrete particles and has the porosity of $13.49 \%$ (Figure 3(c)). Some of the reactive products may solidify into a semimelt state when barrel length is $300 \mathrm{~mm}$. The coating layer deposited using barrel length of $400 \mathrm{~mm}$ was denser (Figures 3(d) and 3(e)) and had a porosity of $0.92 \%$ (Figure 3(f)) [35]. However, a lot of coarse inclusions in the form of nondeformed discrete particles were detected.

The microstructure of the coatings deposited using barrel length of $500 \mathrm{~mm}$ is dense and homogeneous (Figures $3(\mathrm{~g}$ ) and $3(\mathrm{~h})$ ). The coatings (barrel length: $500 \mathrm{~mm}$ ) had porosity of $0.24 \%$ (Figure $3(\mathrm{i})$ ).

Comparing the microstructures presented in Figure 3, it can be seen that the apparent porosity decreases with the increase of barrel length from 300 to $500 \mathrm{~mm}$ and dense coatings with porosity $0.24 \%$ are produced at barrel length of $500 \mathrm{~mm}$. The absence of porosity and a largely deformed splat structure in Figure 3(h) confirms that barrel length was used correctly to achieve an optimal dense material.

The spectrum shown in Figure 1(d) indicates that the process used in producing the titania feedstock resulted in the presence of Ti with hexagonal structure. Figure 4 shows the XRD patterns of the titanium coatings.

The phase analysis shows that after spraying the main phase in the coatings layer is $\mathrm{Ti}$ with hexagonal structure (Figure 4). The distinguished interplanar spacing calculated from reflections makes it possible to identify the following phases in the coatings: $\mathrm{TiO}$ with a cubic lattice, $\mathrm{Ti}_{2} \mathrm{O}_{3}$ with hexagonal structure, $\mathrm{Ti}_{3} \mathrm{O}_{5}$ with orthorhombic structure, anatase with tetragonal structure, and rutile with tetragonal structure. 


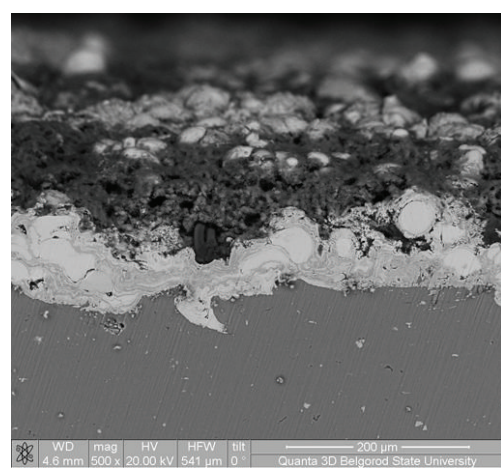

(a)

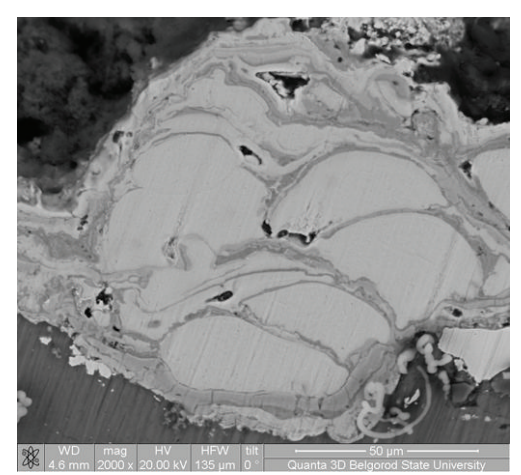

(b)

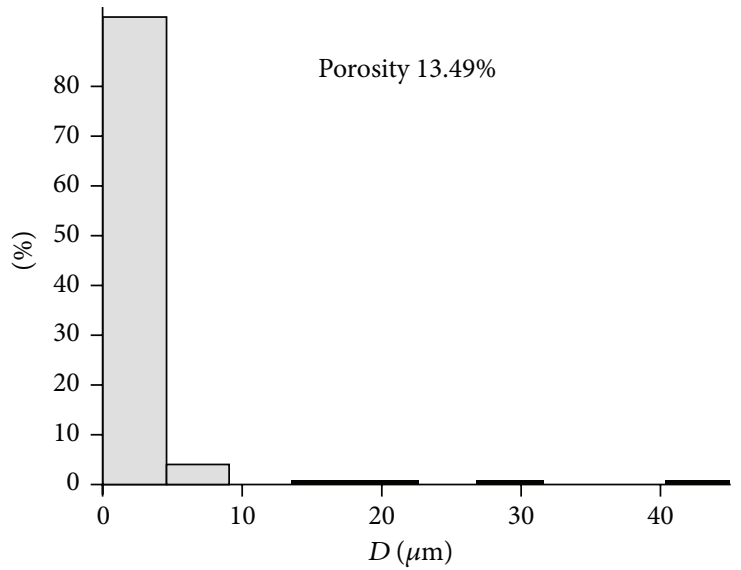

(c)

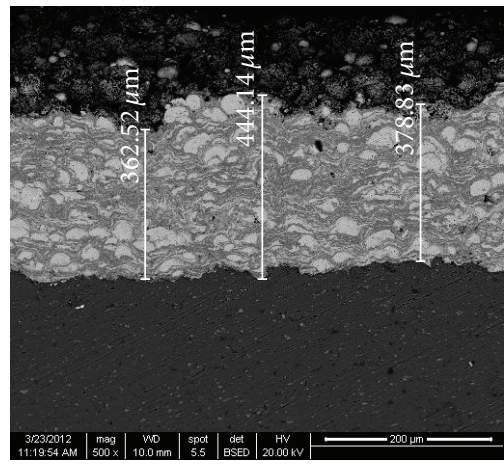

(d)

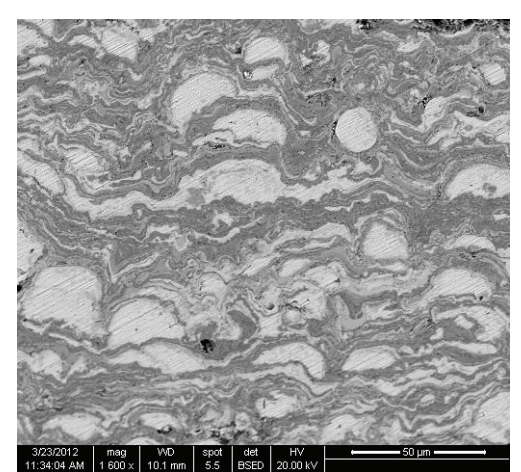

(e)

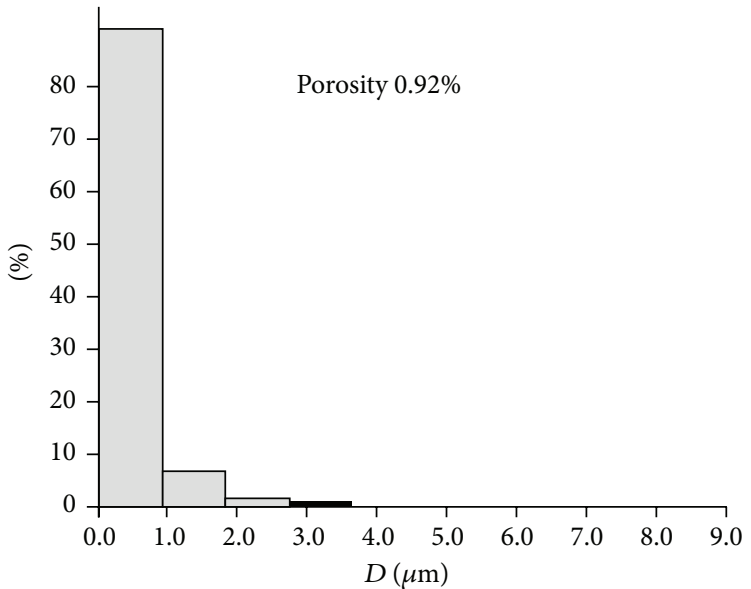

(f)

Figure 3: Continued. 


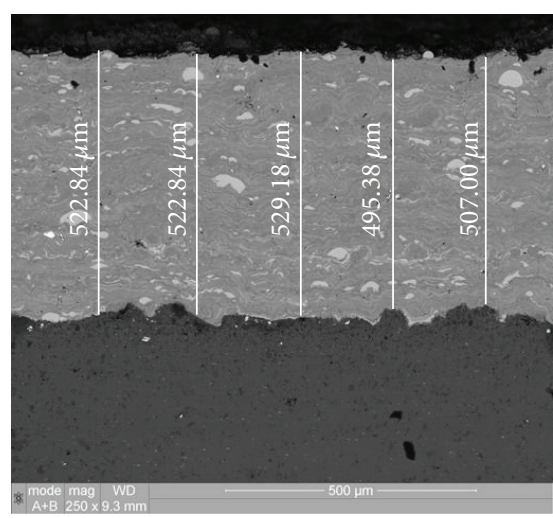

(g)

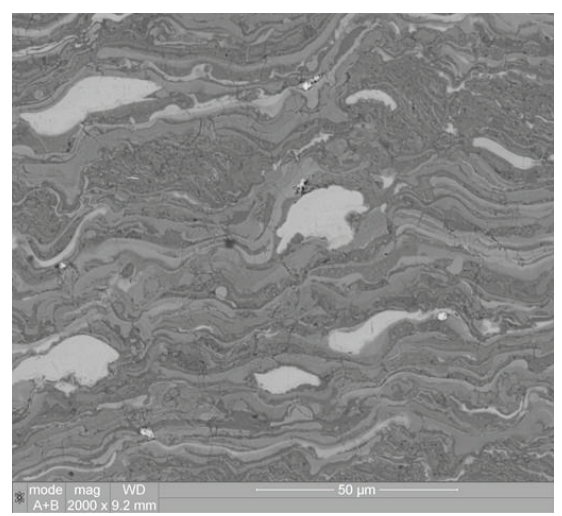

(h)

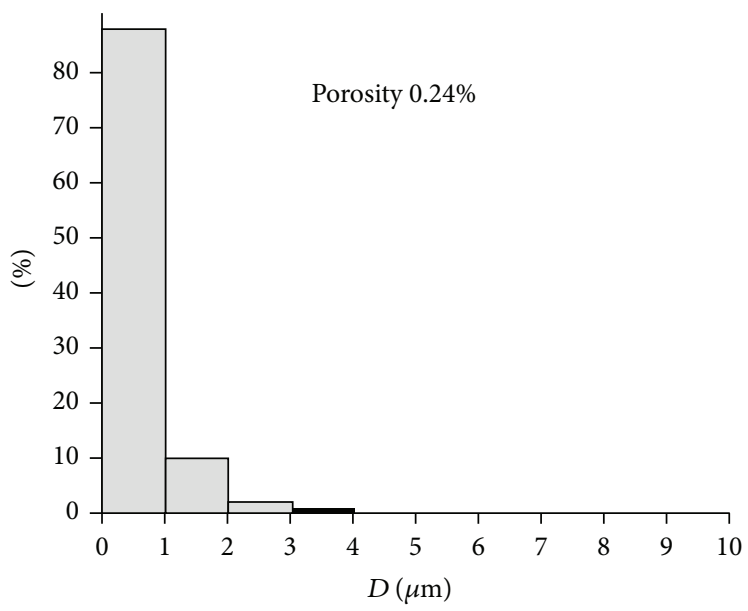

(i)

FIGURE 3: SEM micrographs of cross sections of titanium-based coatings and histogram plot of the pore size distribution: ((a), (b), and (c)) barrel length $300 \mathrm{~mm}$; ((d), (e), and (f)) barrel length $400 \mathrm{~mm}$; ((g), (h), and (i)) barrel length $500 \mathrm{~mm}$ (SEM, backscattered electron mode).

Titanium exists in different oxidation states: $\mathrm{Ti}^{2+}, \mathrm{Ti}^{3+}$, and $\mathrm{Ti}^{4+}$. The corresponding oxides are $\mathrm{TiO}, \mathrm{Ti}_{2} \mathrm{O}_{3}, \mathrm{Ti}_{3} \mathrm{O}_{5}$, $\mathrm{TiO}_{2}$, and a complex combination of oxides called Magneli phases, which correspond to the general formula $\mathrm{Ti}_{n} \mathrm{O}_{2 n-1}$ $(n>3)$. The Magneli phases are formed when $\mathrm{TiO}_{2}$ is annealed in a reducing atmosphere [36].

It can be seen (Figure 4) that the coating fabricated with a barrel length of $300 \mathrm{~mm}$ is mainly composed of unreacted $\mathrm{Ti}$, $\mathrm{TiO}$, and $\mathrm{Ti}_{2} \mathrm{O}_{3}$. When the barrel length increases to $400 \mathrm{~mm}$, the coating is composed of unreacted $\mathrm{Ti}, \mathrm{TiO}, \mathrm{Ti}_{2} \mathrm{O}_{3}$, and $\mathrm{Ti}_{3} \mathrm{O}_{5}$. This is because, during the spraying process, the reaction between particles and gas is not complete and the intermediate and/or metastable oxides may be produced at a faster rate $[37,38]$. With the increase of the barrel length up to $500 \mathrm{~mm}$, the coating is composed of some unreacted $\mathrm{Ti}, \mathrm{TiO}$, and $\mathrm{Ti}_{2} \mathrm{O}_{3}$, and, as a new component, $\mathrm{TiO}_{2}$ (anatase, rutile) was found in the coating. It means that, with the increase of the barrel length, more reaction time (higher temperature) and more reaction gas can be provided for the reactions of oxidation $[39,40]$. As a result, more Ti oxides and stable $\mathrm{Ti}$ oxides will be produced.

An average microhardness of the coatings is given in Table 1. A wide range of hardness values in obtained coatings is caused by their different phase composition and porosity.
TABLE 1: Microhardness of samples, data based on $\mathrm{HV}_{0.05}$ test.

\begin{tabular}{lc}
\hline Substrate (aluminium 6063) & $100 \pm 25$ \\
\hline $\begin{array}{l}\text { Titanium-based coatings } \\
\text { Barrel length, mm }\end{array}$ \\
\hline 300 & $685 \pm 250$ \\
\hline 400 & $820 \pm 250$ \\
\hline 500 & $1300 \pm 250$ \\
\hline
\end{tabular}

The fine powder fraction is almost completely melted, while the larger particles fraction might remain solid. In practice, this leads to the formation of a material with some local differences in mechanical properties.

The microhardness increases with the increase of barrel length in the range of $300-500 \mathrm{~mm}$. This relationship can be explained as follows: with the increase of barrel length, more reaction time and more reactants are provided. This promotes the reactions of Ti with oxygen in the air and more Ti composite hard phases may be synthesized as mentioned in the former section [39].

Microhardness was similar in experiment \#1 (barrel length: $300 \mathrm{~mm}$ ) and in experiment $\# 2$ (barrel length: 

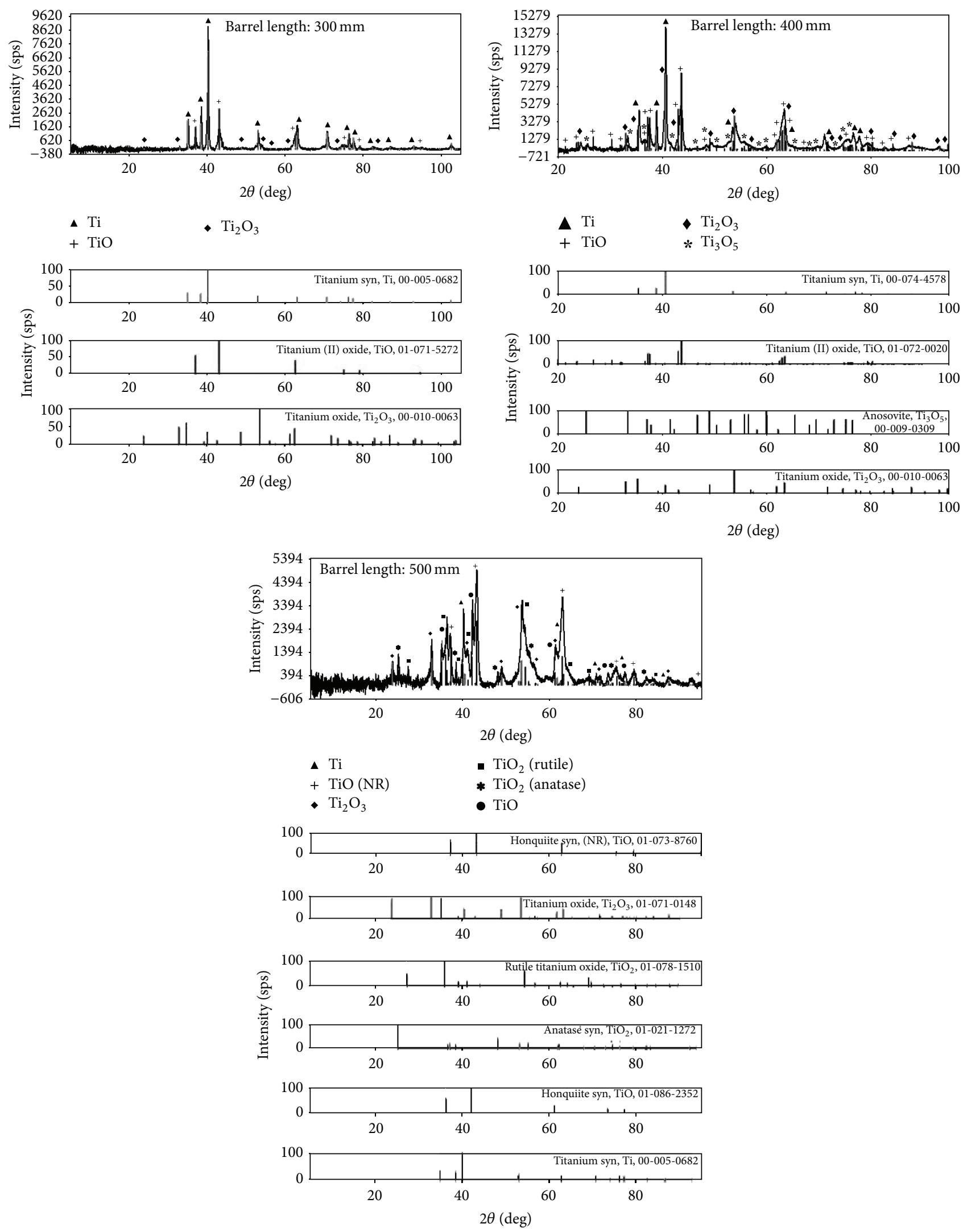

FIGURE 4: XRD pattern of the titanium-based coatings fabricated with different barrel lengths. 
$400 \mathrm{~mm}$ ), ranging from 435 to $1070 \mathrm{HV}_{0.05}$. These coatings were fairly porous and their cross section micrographs (Figures 3(a)-3(f)) clearly revealed numerous spherically shaped particles, which is an indication of the lack of plastic deformation.

Thus, strain hardening was not prevalent, particularly when compared to denser coatings, as for barrel length of $500 \mathrm{~mm}$. In these situations, the microhardness values increase significantly $\left(1300 \pm 250 \mathrm{HV}_{0.05}\right)$. The highest value recorded was $1550 \mathrm{HV}_{0.05}$ and it was observed in experiment \#3 (barrel length: $500 \mathrm{~mm}$ ). In particular, under these conditions, a significant amount of material jetting occurred (Figures $3(\mathrm{~g})$ and $3(\mathrm{~h})$ ). This facilitated the plastic deformation of the titanium particles and, consequently, a denser coating is produced. Thus, the likelihood of the decreased coating microhardness caused by weaker interparticle bonding is reduced. Second, a tamping effect in which the initially sprayed particles would be further flattened and strainhardened by the subsequent impacting particles would occur. It means that a significant strain hardening would take place. As a result, the coating microhardness would increase [40].

\section{Conclusions}

In the present investigation, the multichamber detonation sprayer was used for the deposition of the titanium-based coatings of titanium powder on aluminium substrate. The multichamber gas-dynamic sprayer (MCDS) has replaceable barrels (lengths 300, 400, and $500 \mathrm{~mm}$ ) and operates on a fuel mixture of gases: propane (30\%) + butane (70\%), oxygen, and air. It was established that the apparent porosity and microhardness increase with an increase in barrel length from 300 to $500 \mathrm{~mm}$ and the densest coatings with the porosity of $0.24 \%$ and microhardness of $1300 \pm 250 \mathrm{HV}_{0.05}$ are produced at barrel length of $500 \mathrm{~mm}$. At that spraying experiment, the fine powder particles were heated and deformed to a state of fine lamellae, and they filled the spacing between the coarse particles to form a dense homogeneous coating. Also it has been found that, with the increase of barrel length up to $500 \mathrm{~mm}, \mathrm{TiO}_{2}$ (anatase, rutile) appear in the coating besides $\mathrm{Ti}, \mathrm{TiO}$, and $\mathrm{Ti}_{2} \mathrm{O}_{3}$. This corresponds to the following phase transformation taking place during the spraying: $\mathrm{TiO} \rightarrow \mathrm{Ti}_{2} \mathrm{O}_{3} \rightarrow \mathrm{Ti}_{3} \mathrm{O}_{5} \rightarrow$ phase Magnelli $\rightarrow$ $\mathrm{TiO}_{2}$. It means that, with the increase of barrel length, more reaction time (higher temperature) and reaction gas can be provided for reactions of oxidation. It was established that the microhardness growth associated with a change in porosity, with the quantitative phase ratio in the coatings, and with the appearance of $\mathrm{TiO}_{2}$ (anatase, rutile).

\section{Conflict of Interests}

The authors declare that there is no conflict of interests regarding the publication of this paper.

\section{Acknowledgments}

This work was carried out on the equipment of the Joint Research Center "Diagnostics of Structure and Properties of
Nanomaterials" of Belgorod State National Research University. This work was financially supported by the Ministry of Education and Science of the Russian Federation under Project no. 14.594.21.0010 (Code RFMEFI62114X0005).

\section{References}

[1] J. W. Diggle, T. C. Downie, and C. W. Goulding, "Anodic oxide films on aluminum," Chemical Reviews, vol. 69, no. 3, pp. 365405, 1969.

[2] S. Wernick, R. Pinner, and P. G. Sheasby, The Surface Treatment and Finishing of Aluminium and Its Alloys, vol. 1, ASM Handbook, ASM International, Novelty, Ohio, USA, 5th edition, 1987.

[3] E. H. Hollingsworth and H. Y. Hunsicker, "Corrosion of aluminum and aluminum alloys," in ASM Handbook, vol. 13, pp. 583609, ASM International, Metals Park, Ohio, USA, 9th edition, 1987.

[4] H. Schiht, H. Hildebrand, and U. Szumanuski, "Highly corrosion-resistant reflection layer systems on substrates," GB Patent 2112815, 1983.

[5] A. Vovsi, N. Kashpur, and O. Rashevic, Deposition of Coatings in Vacuum, Zinatne, Riga, Latvia, 1986.

[6] J. A. Mountford, "Titanium-properties, advantages and applications solving the corrosion problems in marine service," Tech. Rep. 02170, U.S. Navy \& Industry Corrosion Technology Information, 2001, RUST 2001.

[7] R. R. Boyer, "An overview on the use of titanium in the aerospace industry," Materials Science and Engineering A, vol. 213, no. 1-2, pp. 103-114, 1996.

[8] O. E. M. Pohler, "Unalloyed titanium for implants in bone surgery," Injury, vol. 31, no. 4, pp. D7-D13, 2000.

[9] M. J. Donachie Jr., Titanium: A Technical Guide, ASM International, Materials Park, Ohio, USA, 2nd edition, 2000.

[10] D. K. Christoulis, S. Guetta, V. Guipont, and M. Jeandin, "The influence of the substrate on the deposition of cold-sprayed titanium: an experimental and numerical study," Journal of Thermal Spray Technology, vol. 20, no. 3, pp. 523-533, 2011.

[11] T. Kinos, S. L. Chen, P. Siitonen, and P. Kettunen, "Densification of plasma-sprayed titanium and tantalum coatings," Journal of Thermal Spray Technology, vol. 5, no. 4, pp. 439-444, 1996.

[12] ASM Handbook Volume 2: Properties and Selection: Nonferrous Alloys and Special-Purpose Materials, ASM International, 1992.

[13] J. A. Mountford Jr., "Titanium-properties, advantages and applications solving the corrosion problems in marine service," in Proceedings of the CORROSION, Paper Number 02170, NACE International, Denver, Colo, USA, April 2002.

[14] W.-M. Zhao, C. Liu, L.-X. Dong, and Y. Wang, "Effects of arc spray process parameters on corrosion resistance of $\mathrm{Ti}$ coatings," Journal of Thermal Spray Technology, vol. 18, no. 4, pp. 702-707, 2009.

[15] Y. Yao, Z. Wang, Z. Zhou, S. Jiang, and J. Shao, "Study on reactive atmospheric plasma-sprayed in situ titanium compound composite coating," Journal of Thermal Spray Technology, vol. 22, no. 4, pp. 509-517, 2013.

[16] A. C. Jones and M. L. Hitchman, "Overview of chemical vapour deposition," in Chemical Vapour Deposition: Precursors, Processes and Applications, chapter 1, pp. 1-36, RSC Publishing, 2008.

[17] R. S. Lima and B. R. Marple, "Nanostructured and conventional titania coatings for abrasion and slurry-erosion resistance 
sprayed via APS, VPS and HVOF," in Proceedings of the Thermal Spray Connects: Explore Its Surfacing Potential (ITCS '05), C. C. Berndt, Ed., pp. 552-557, ASM International, Basel, Switzerland, May 2005.

[18] J. Kawakita, S. Kuroda, T. Fukushima, H. Katanoda, K. Matsuo, and H. Fukanuma, "Dense titanium coatings by modified HVOF spraying," Surface and Coatings Technology, vol. 201, no. 3-4, pp. 1250-1255, 2006.

[19] K. Kim, M. Watanabe, and K. Mitsuishi, "Microstructure observation on the interface between warm spray deposited titanium powder and steel substrate," in Proceedings of the Thermal Spray: Crossing Borders (ITSC '08), E. Lugscheider, Ed., pp. 1289-1294, ASM International, Maastricht, The Netherlands, June 2008.

[20] S. H. Zahiri, C. I. Antonio, and M. Jahedi, "Elimination of porosity in directly fabricated titanium via cold gas dynamic spraying," Journal of Materials Processing Technology, vol. 209, no. 2, pp. 922-929, 2009.

[21] H. R. Wang, B. R. Hou, J. Wang, Q. Wang, and W.-Y. Li, "Effect of process conditions on microstructure and corrosion resistance of cold-sprayed Ti coatings," Journal of Thermal Spray Technology, vol. 17, no. 5-6, pp. 736-741, 2008.

[22] J. Kawakita, H. Katanoda, M. Watanabe, K. Yokoyama, and S. Kuroda, "Warm spraying: an improved spray process to deposit novel coatings," Surface and Coatings Technology, vol. 202, no. 18, pp. 4369-4373, 2008.

[23] K.-H. Kim, S. Kuroda, M. Watanabe, R.-Z. Huang, H. Fukanuma, and H. Katanoda, "Comparison of oxidation and microstructure of warm-sprayed and cold-sprayed titanium coatings," Journal of Thermal Spray Technology, vol. 21, no. 3-4, pp. 550560, 2012.

[24] T. Schmidt, F. Gärtner, H. Assadi, and H. Kreye, "Development of a generalized parameter window for cold spray deposition," Acta Materialia, vol. 54, no. 3, pp. 729-742, 2006.

[25] T. Marrocco, D. G. McCartney, P. H. Shipway, and A. J. Sturgeon, "Production of titanium deposits by cold-gas dynamic spray: numerical modeling and experimental characterization," Journal of Thermal Spray Technology, vol. 15, no. 2, pp. 263-272, 2006.

[26] A. Papyrin, V. Kosarev, S. Klinkov, A. Alkhimov, and V. Fomin, Cold Spray Technology, Elsevier, Amsterdam, The Netherlands, 2007.

[27] M. Kovaleva, Y. Tyurin, O. Kolisnichenko, M. Prozorova, and M. Arseenko, "Properties of detonation nanostructured titanium-based coatings," Journal of Thermal Spray Technology, vol. 22, no. 4, pp. 518-524, 2013.

[28] G. Sridhar, S. G. Chowdhury, and N. G. Goswami, Materials Characterization Techniques: Principles and Applications, 1999.

[29] ASTM Standard, "Standard methods of preparing metallographic specimens," in Annual Book of ASTM Standards E-3-86, vol. 03.01, p. 12, American Society for Metals, 1986.

[30] M. Kovaleva, Y. Tyurin, N. Vasilik et al., "Deposition and characterization of $\mathrm{Al}_{2} \mathrm{O}_{3}$ coatings by multi-chamber gasdynamic accelerator," Surface and Coatings Technology, vol. 232, pp. 719-725, 2013.

[31] N. Vasilik, N. Tyurin, and O. Kolisnichenko, "Method for gasdynamic detonating speedup of powders and device for its implementation," RU Patent 2506341, 2012.

[32] N. J. Vasilik, Y. N. Tyurin, O. V. Kolisnichenko, M. G. Kovaleva, M. S. Prozorova, and M. Y. Arseenko, "Properties, peculiarities and applications of powder coatings formed by multi-chamber detonation sprayer," Applied Mechanics and Materials, vol. 467, pp. 179-184, 2014.
[33] G. J. Moskal, “The porosity assessment of thermal barrier coatings obtained by APS method," Journal of Achievements in Materials and Manufacturing Engineering, vol. 20, no. 1-2, pp. 483-486, 2007.

[34] T. Hussain, D. G. McCartney, P. H. Shipway, and T. Marrocco, "Corrosion behavior of cold sprayed titanium coatings and free standing deposits," Journal of Thermal Spray Technology, vol. 20, no. 1-2, pp. 260-274, 2011.

[35] M. Kovaleva, Y. Tyurin, M. Arseenko, V. Sirota, and I. Pavlenko, "Titanium nanostructured coatings obtained by multi-chamber gas-dynamic accelerator," in Proceedings of the 5th International Conference Nanocon, Brno, Czech Republic, October 2013, http://www.nanocon.eu/.

[36] M. Miyayama, K. Koumoto, and H. Yanagida, Engineered Materials Handbook, Volume 4: Ceramics and Glasses, ASM International, Materials Park, Ohio, USA, 1991.

[37] Y. Yao, Z. Wang, Z. Zhou, S. Jiang, and J. Shao, "Study on reactive atmospheric plasma-sprayed in situ titanium compound composite coating," Journal of Thermal Spray Technology, vol. 22, no. 4, pp. 509-517, 2013.

[38] R. S. Lima and B. R. Marple, "Optimized HVOF titania coatings," Journal of Thermal Spray Technology, vol. 12, no. 3, pp. 360-369, 2003.

[39] H. Okamoto, "O-Ti (Oxygen-Titanium)," Journal of Phase Equilibria and Diffusion, vol. 32, no. 5, pp. 473-474, 2011.

[40] W. Wong, E. Irissou, A. N. Ryabinin, J.-G. Legoux, and S. Yue, "Influence of helium and nitrogen gases on the properties of cold gas dynamic sprayed pure titanium coatings," Journal of Thermal Spray Technology, vol. 20, no. 1-2, pp. 213-226, 2011. 

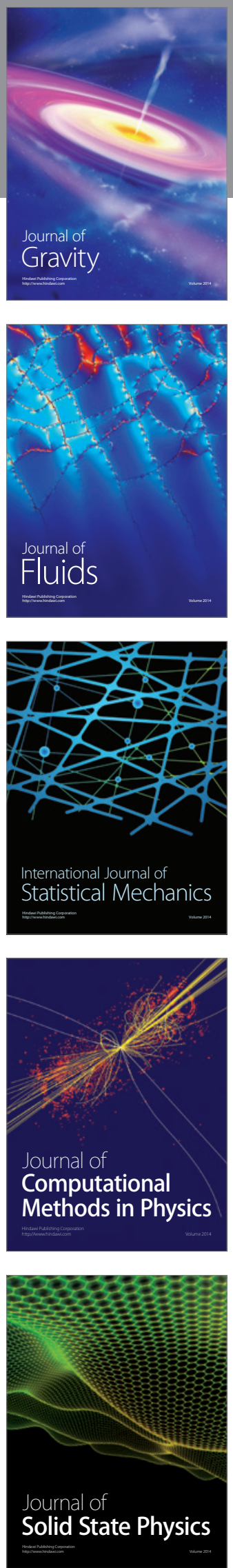

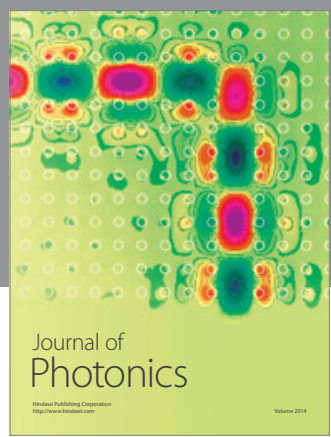

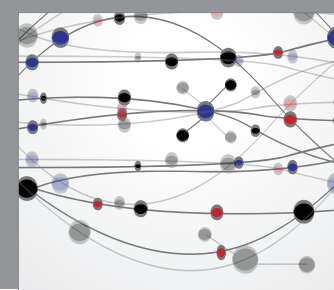

The Scientific World Journal

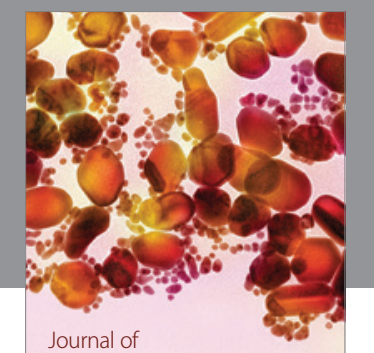

Soft Matter
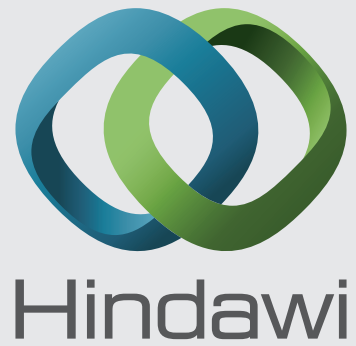

Submit your manuscripts at

http://www.hindawi.com
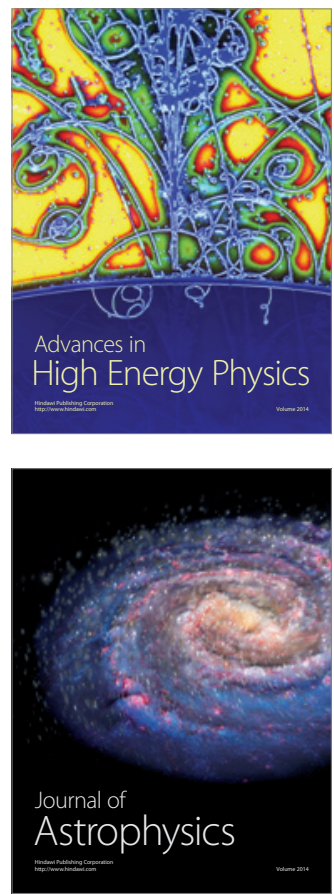
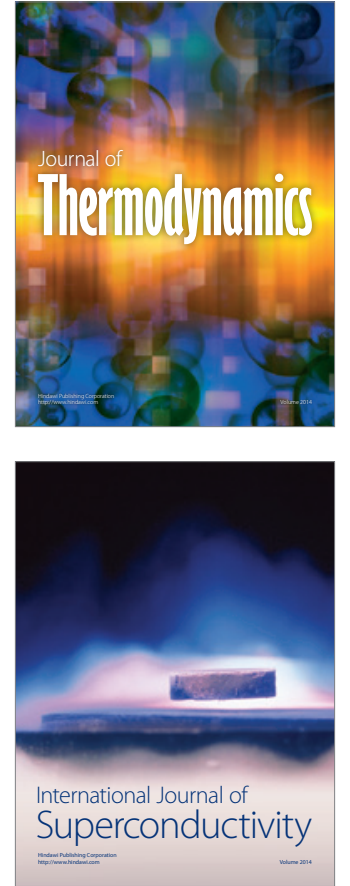
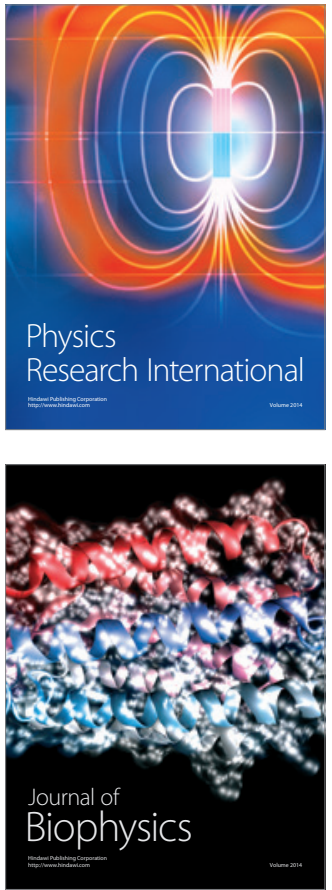
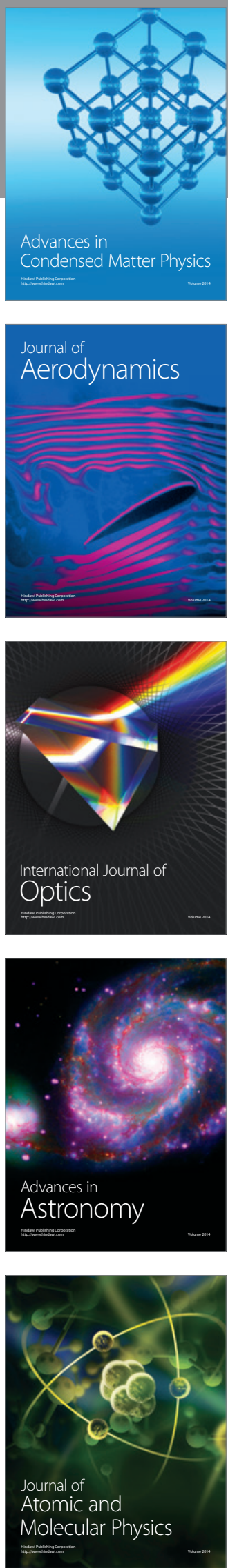